“[T]hey Say Black Men Won't Make It, but I Know I'm Gonna Make It”: Ethnic and Racial Identity Development in the Context of Cultural Stereotypes

Niobe Way and Onnie Rogers

Preprint:

Way, N., \& Rogers, L. O. (2015). “[T]hey say Black men won't make it, but I know I'm gonna make it": Ethnic and racial identity development in the context of cultural stereotypes. In K. McLean \& M. Syed (Eds.) Oxford handbook of identity development (pp. 269-285). New York, NY: Oxford University Press. 


\section{“[T]hey Say Black Men Won’t Make It, but I Know I’m Gonna Make It": Ethnic and Racial Identity Development in the Context of Cultural Stereotypes}

Niobe Way and Onnie Rogers

Abstract

For more than a century, scholars have defined the self as a social phenomenon dependent on relationships and embedded within a sociohistorical context. Yet a review of the empirical study of identity over the past forty years reveals significant divergence from this individual-in-context perspective. This chapter returns to the sociocultural roots of identity development study, reviewing empirical research with adolescents from diverse ethnic and racial backgrounds and the works of others that focus on how cultural stereotypes about race, ethnicity, gender, sexuality, social class, and nationality intersect to form the context within which individuals construct, experience, and interpret their ethnic and racial identities. This review makes evident that identity is simultaneously personal and social and that stereotypes about social categories are a significant link that binds them. The chapter concludes with a discussion of the implications of these findings for research and theory on identity development and for the field of psychology more broadly.

Keywords: Identity, culture, stereotypes, intersectionality

For more than a century, scholars have defined the self as a social phenomenon dependent on relationships and embedded within a sociohistorical context (James, 1890; Cooley, 1902; Mead, 1934). Erik Erikson, a seminal theorist of identity development said that identity is "“located' in the core of the individual and yet also in the core of his communal culture" (Erikson, 1968, p. 22; 
emphasis in original). Yet a review of the empirical study of identity development over the past forty years reveals a significant divergence from this individual-in-context perspective. Identity has been, for the most part, extracted from its relational and sociohistorical roots and is typically conceptualized either as an individual-level process (i.e., personal identity) or as a social process (i.e., social identity) that can be separated from the contexts and cultures in which it exists. This representation fails to acknowledge the contextually embedded nature of identity and the ways in which identities are, as Erikson indicated, a reflection of both the individual and of his or her "communal culture."

In this chapter, we return to the sociocultural roots of identity. Our empirical research and the works of many others that attune to identity development in context and culture reveal the ways in which stereotypes about race, gender, sexuality, social class, and nationality serve as context within which individuals construct, experience, and interpret their identities and are thus an integral part of identity development, including ethnic and racial identity development (Brown \& Gilligan, 1992; Chu, 2004; Cunningham, 1999; Lei, 2003; Nasir, 2011; Robinson \& Ward, 1991; Rogers, 2013; Spencer, Dupree, \& Hartmann, 1997; Way, 2011; Way, Hernandez, Rogers, \& Hughes, 2013; Way, Santos, Niwa, \& Kim-Gervy, 2008). The data make evident that identity is simultaneously personal and social and that the stereotypes about social categories that exist in American culture (and elsewhere) are a significant link that binds them. We discuss in this chapter the implications of these findings for research and theory on identity development, as well as for the field of psychology more broadly. The data we present from our own studies comes from four of our longitudinal and mixed method studies ${ }^{1}$ that we have conducted with students attending six middle schools and three high schools located in two cities in the United 
States. Our samples include White, Black, Dominican, Chinese, and Puerto Rican adolescents and attend schools in which the majority of the students qualified for free/reduced lunch.

\section{Identity Development}

Erikson (1968) defined identity as "a subjective sense of invigorating sameness and continuity" (p. 19), referring to the integration of personal experiences, social roles and expectations, and desires and ideals into a coherent sense of self. This foundational definition has given rise to two broad, and largely distinct, perspectives toward the study of identity: (a) "personal identity," which emphasizes an individual's life story, experiences, and choices; and (b) "social identity," which is oriented toward understanding one's experience as a function of social group membership. Both orientations focus on the extent to which one has explored an identity, with the implicit assumption that the meaning of identity (or the way it has been or is being defined by the individual) is rooted in how much one likes or is attached to the identity, how much one has thought about or engaged in activities related to one's identities, and/or considered future roles related to one's identity. The emphasis in both of these approaches, particularly in the study of social identities, has been on asking "how much" rather than "what or why" questions. Questions that are rarely asked include: what is the meaning of ethnic or racial identity, or why are particular identities maintained or why are other identities rejected?

The study of personal identity focuses on identity as "an anchor in the sea of possibilities" the world has to offer, a lever that enables one to control his or her life direction (Schwartz, 2005, p. 294). This line of research is most often linked to an Eriksonian perspective, in part due to James Marcia's (1966) identity status paradigm (see Crocetti \& Meeus, this volume; Kroger, this volume). Marcia was first to operationalize Erikson's theory using the concepts of exploration and commitment. According to Marcia's model, the ideal identity, 
identity achievement, is the product of high levels of exploration — learning about the self and considering options for who one wants to be —-followed by a strong, stable commitment $-\mathrm{a}$ clear view of one's self and purpose. En route to an achieved identity, individuals may pass through or fixate in less optimal statuses: a foreclosed identity, defined by strong convictions and attitudes (high commitment) that are established in the absence of exploration; a state of moratorium, with high levels of exploration but little conviction or commitment to any particular self story; or the diffused identity in which self-discovery is halted (or perhaps yet to be initiated), demonstrated by low levels of exploration and commitment. The assumption is that individuals need to explore their options and make steadfast commitments in order for development to proceed optimally. Early studies found the combination of high exploration and commitment to be associated with positive indicators of adolescent adjustment, such as high self-esteem and positive and productive social behaviors and relationships (Marcia, 1966; Orlofsky, Marcia, \& Lesser, 1973). More recent work investigates the subjective construction of one's life story or life choices, such as chosen career paths (e.g., Cote \& Schwartz, 2002 McAdams, 1990; 2001).

In essence, research on personal identities focuses on how individuals grapple with the "sameness and continuity" of the self through time and space (e.g., Cote \& Schwartz, 2002; McAdams, 1990; 2001). Collectively, these findings indicate that exploration and the opportunity for introspection are essential for formulating a coherent identity and that such exploration is ongoing throughout adolescence and adulthood (e.g., McAdams, 2001; Syed \& Azmitia, 2009). What this work rarely tells us, however, is how social categories, such as gender, race and ethnicity, and sexuality, shape the pathway of personal identification or how micro- and macrocontexts shape the construction of the self or personal identity (Azmitia, Syed, \& Radmacher, 2008; Hammack \& Cohler, 2011). 
Identity research also focuses on "social identity." If personal identity is concerned with an individual's sense of "me-ness," then social identity is attuned to the sense of "we-ness" that one develops as a result of membership in social categories, such as race/ethnicity or gender (Azmitia et al., 2008). Tajfel (1981) defined social identity as "that part of an individual's selfconcept which derives from his knowledge of his membership of a social group together with the value and emotional significance attached to that membership" (p. 63). This framing recognizes that the self is relational, extending the concept of identity beyond the individual. Although a full review of social identity theory (Tajfel \& Turner, 1986) and its measurement frameworks is beyond the scope of this chapter (see Hammack, this volume), this literature, in sum, highlights the individual variability in social group identifications (See Ashmore, Deaux, \& McLaughlinVolpe, 2004, for a review.) Individuals of the same racial or ethnic group, for example, vary in the degree to which they identify with their race or ethnicity (e.g., centrality/importance), how they feel about being a member of the racial or ethnic group (e.g., evaluation/regard), and the racial or ethnic group beliefs or ideologies that they endorse (Ashmore et al., 2004; Sellers, Smith, Shelton, Rowley, \& Chavous, 1998). As with the personal identity literature, studies on social identity indicate that a strong sense of social group membership (i.e., high levels of engagement and pride) is an essential aspect of healthy development, with significant links to self-esteem and academic achievement (e.g., Chavous et al., 2003; Phinney, 1990; Quintana, 2007; Seaton, Scottham, \& Sellers, 2006).

The research on both personal and social identities has significantly extended our understanding of identity development and its psychological, social and academic correlates. Yet the division of identity into "personal" and "social" has ironically reduced its conceptualization to an individual-level construct or to a process that occurs within the individual rather than within 
a relationship, a context, and a culture (see Korobov, this volume). Even though scholarship acknowledges that the self is shaped by social forces and occasionally examines the cultural context (e.g., the dimension of public regard found in Sellers' Multidimensional Model of Racial Identity), the focus is typically on the self. For example, in the study of personal identity, career pathways are examined as a process of individual choice, with little consideration of how social and cultural expectations inform — and constrain — the choices that one perceives possible. Even the few personal identity researchers who have examined the cultural context (e.g., McAdams, 2013) do not examine the macrocontext of beliefs and expectations about social categories (e.g., race, gender, class) and how this macrocontext shapes personal identities.

A similar focus on the self is evident in social identity research. Current empirical work examines the extent to which an individual identifies with or is attached to his or her gender or race, for example, rather than how a culturally perpetuated set of stereotypes shape and infuse the meaning of liking or not liking one's gender or racial group. Although early studies of ethnic and racial identity focused on how individuals spoke about and experienced their racial and ethnic groups in context (e.g., Cross, 1991; Phinney, 1992) and laid the foundation for the measures of ethnic and racial identity (Phinney, 1992; Sellers et al., 1998), later studies, with a few exceptions (e.g., Umaña-Taylor, 2004; Syed \& Azmitia, 2008; 2010), have downplayed the context and focused instead on individual differences in "stages" or "levels" of identity development. These studies have provided us with insight into the ways in which different levels of engagement and affect toward one's social group, for example, is associated with adjustment, but not into how these levels develop or exist within a relational or cultural context.

Another limitation of the social identity research is its tendency to treat race, ethnicity, gender, and other social categories as "natural" and static rather than as socially constructed and 
dynamic. Whereas race, for example, is defined as a set of phenotypic characteristics that are shared by a group of individuals (Hirschfeld, 1996; Paabo, 2001), and ethnicity is defined as the geographical location or language that is shared by a group of people (e.g., Quintana, 2007Slaughter-Defoe, 2012), one's racial and ethnic identity is bound to the culturally derived meaning and significance of race and ethnicity within a set of geographical, social, and political realities rather than simply by a biological reality (Hirschfeld, 1996; Paabo, 2001; Segall, 1999). Racial identity, in other words, is not merely reflective of one's membership in the racial category of, for example, Black, but also by the social meaning of being Black within a particular context of, for example, the United States.

A similar case can be made for gender. Investigating, for example, when a child categorizes herself as a girl or how good she feels about or the extent to which she is attached to being a girl are important questions. Yet they only mark a part of gender identity and do not offer information regarding how gender identity is shaped by the cultural constructs of girlhood and femininity within a particular context. In the development of social identity, ethnic, racial, and gender labels, for example, are plugged into and activated by culturally and contextually charged meanings of those ethnic, racial, and gender labels. According to theory and research, Chinese American people, for example, do not simply have an experience of being Chinese American; they experience being Chinese American within a larger culture and context that regularly communicates to them what it means to be Chinese American. To investigate ethnic, racial, and gender identities without examining the social nature of social identities, in other words, is to downplay the social in social identities.

There are, however, a few scholars who have indeed challenged these divisions by examining racial identity as a process of responding to a larger cultural narrative about race and 
ethnicity in American culture (e.g., Cunningham, 1999; Nasir, 2011; Nasir \& Shah, 2011; Spencer et al., 1997; Spencer, Fegley, Harpalani, \& Seaton, 2004; Stevenson, 1997). Spencer and colleagues (1997) tackle this gap from a theoretical standpoint with the phenomenological variant of ecological systems theory (P-VEST). P-VEST positions the child as an active agent, interpreting and responding to cultural stereotypes. These responses are referred to as "coping strategies" and may be reactive and counterproductive or proactive, positively challenging cultural stereotypes, expectations, and ideals that are harmful.

Identity, then, is the result of one's ongoing response patterns, but, most importantly, the strategies that youth select—and thus the identities that emerge — are tied to the risks and opportunities presented to them. For example, a young Black male in low-income, violent neighborhood may embrace a hypermasculine identity of toughness and anger to shield himself from the physical and emotional vulnerabilities of his environment (Cunningham, 1999; Spencer et al., 2004). In other words, Black males who don the image of the "cool pose"-stoic, quick to anger, and aggressive - are not merely accepting a "negative identity" but a protective shield as they actively negotiate a set of environmental stressors and risk factors that expose their vulnerability and threaten their livelihood. Similarly, the Black youth who constructs a "raceless" identity to achieve in school (Fordham, 1988) does so in response to a racist context that questions his intelligence and thus necessitates such a strategy (see Cooper et al., this volume). The few studies of the cultural context of social identities have been, for the most part, limited to Black youth and thus we know little about how the social identities of Asian, Latino, and White youth are also intimately shaped by culture and context (Steele, 2011).

Apart from these exceptions, the empirical response to Erikson's (1968) cultural, historical, and contextual theory of identity has been to ignore the "psychosocial relativity" of 
identity and the dynamic "interplay between the psychological, the social, the developmental, and the historical" (Erikson, 1968, p. 23). It has been a response that takes identity development, as well as race, ethnicity, and other social categories, out of context. A return to Erikson's (1968) seminal text, Identity: Youth and Crisis, places identity, as well as race, ethnicity, and other social categories, firmly in culture and in context.

Erikson defined identity development as a "process of simultaneous reflection and observation...by which the individual judges himself in light of what he perceives to be the way in which others judge him" (p. 22). Erikson argued that the self derives its meaning from the other and that, during this peak of identity construction, adolescents are "preoccupied with what they appear to be in the eyes of others" (p. 128). The social "other" more broadly represents society. Suárez-Orozco (2004) argues that cultural expectations and stereotypes function as "social mirrors" reflecting to youth who society expects them to be. In similar form, Spencer and colleagues (1997) contend: "the self is constructed in response to stereotypes and biases" (p. 819). Drawing on Vygotskian theory, Nasir and Shah (2011) construct stereotypes as "cultural artifacts" or tools that youth use to make sense of their identities. Thus, it is the interplay of the self and other, the self reflected "in the eyes of others," that constitutes identity. Identity development, in other words, is socially constructed, relational, and inextricable linked to society and its members.

Erikson (1968) also underscores that identity formation involves the avoidance of the negative identity that is projected onto the self about the self. Thus, identity is not only about "becoming" (i.e., achievement) but also about "not becoming" (i.e., avoidance) (Way et al., 2008). Erikson explains: "The human being, in fact, is warned not to become what he often had no intention of becoming so that he can learn to anticipate what he must avoid" (p. 303). 
Articulating a similar idea, Oyserman, Grant, and Ager (1995) argue that youth possess both an ideal self that they desire to move toward and a feared self they want to avoid. Although Oyserman et al. (1995) do not specify what constitutes the feared self, an Eriksonian interpretation suggests that it is comprised of cultural stereotypes - those negative images, messages, and expectations that "haunt us at night" (Erikson, 1968, p. 22). Conceptualizing identity as relational and as responsive to stereotypes shifts the conversation from what identities look like - the status or stage of identity or the level of group belonging — to the meaning of identity itself; from researching who adolescents are to an investigation of who adolescents $d o$ and do not want to be and how this ideal and feared self informs their identity formation.

Our research with adolescents (Rogers, 2013; Way, 2011; Way et al., 2008; 2013), in fact, reveals the nested relationships that give rise to identity development. The semistructured interviews of the hundreds of adolescents in our studies underscore the ways that cultural stereotypes about race, ethnicity, nationality, gender, sexuality, and social class actively shape and give meaning to adolescents' identities and relationships. Our data, as well as the works of others (Brown \& Gilligan, 1992; Cunningham, 1999; Lei, 2003; Robinson \& Ward, 1991; Nasir \& Shah, 2011; Spencer et al., 2004; Stevenson, 1997; Ward, 1996; Waters, 1996), bring to light three interrelated patterns: (a) the prevalence of stereotypes in adolescents' constructions of their identities, (b) the intersecting nature of different types of stereotypes (e.g., gender and race stereotypes) in the construction of identities, and (c) the ways that adolescents' identities are grounded in not only the desire to become a particular type of person or role but also the desire to avoid, reject, or resist stereotypes associated with their social roles (Way et al., 2008; 2013). In the remainder of this chapter, we illustrate these patterns using data from our research and 
others' and discuss the implications of these findings for research and theory in the study of identity development.

\section{Stereotypes and Identity Development}

Stereotypes are widely held cultural beliefs and expectations, generalized attitudes, or evaluations about individuals who share a social group, such as ethnicity, race, gender, social class, or nationality (Stagnor \& Schaller, 1996). More than mental representations, however, stereotypes are "shared storylines" that are lived and experienced in relationship (Nasir, 2011). Stereotypes transform individuals who possess unique characteristics into caricatures without nuance or variation, such that all individuals within an ethnic or racial group, for example, are homogenized. For example, common stereotypes about African-American youth in the United States are that they have rhythm and are athletic, lazy, dumb, loud, and angry (Fordham, 1993; Ghavami \& Peplau, 2013; hooks, 2004; Stevenson, 1997). Latino youth are similarly stereotyped as lazy and dumb, as well as gang members and drug lords (e.g., López, 2003). Asian-American youth, in contrast, are typically stereotyped as the "model minorities"- smart, quiet, shy, and obedient (Lee, 1994). At the same time, as members of an immigrant group, Asian American immigrant youth are also viewed as dirty, poor, weak, girly, and gay (Chua \& Fujino, 2008; Lei, 2003; Shek, 2006). Stereotypes are not restricted to ethnic, racial, or sexual minorities.

Whiteness in the United States is often stereotyped as being wealthy, successful, physically weak, and gay (Ghavami \& Peplau, 2013; Pascoe, 2007; Perry, 2001).

Research furthermore suggests that stereotypes both shape and infuse identities through codes based on social categories, which are constructed in relationship to each other. For example, studies show that academic achievement is coded as "White," and students of color who excel in school (except for Asians) are deemed "acting White" (Carter, 2006; Cooper et al., 
this volume; Fordham \& Ogbu, 1986). In contrast, "acting Black" means the opposite of "acting White" and refers to speaking in urban slang, dressing in urban style, and listening to hip hop music (Carter, 2006; Delpit, 1995). Nguyen (personal communication, August 3, 2009) described a phenomenon among Asian youth who call themselves "pencils," referencing their Asian-ness on the outside (i.e., their "yellow" skin tone) and Blackness on the inside because they ditch school, listen to hip hop, and get in fights. Nasir and Shah (2011) describe these racial and ethnic contrasts in this way:

As with "Asians are good at math," the notion that "White men can't jump" exemplifies how racialized narratives tend to be inherently relational in character. The inability of White men to jump is only visible because of the (presumed) certainty that non-White men (usually African American men) can jump (p. 30). Such ethnic and racial coding of characteristics, behaviors, and abilities illustrates how cultural stereotypes are relational and infuse self-perceptions and developing identities.

Ethnic and racial stereotypes also operate alongside other social stereotypes, a concept referred to as intersectionality (Ghavami \& Peplau, 2013; Shields, 2008). Intersectionality theory argues that the stereotypes that define social categories intersect with each other to create unique identity constellations (Collins, 2000; Shields, 2008). In other words, neither a "genderless race" nor a "raceless gender" exists; instead, stereotypes are simultaneously "raced" and "gendered" (as well as "classed" and "sexualized"). The stereotypes that characterize Black girls and women are unique and distinct from the stereotypes about Black boys and men. Likewise, White boys and men are stereotyped differently than Asian boys and men. Thus, embedding the study of identity development in cultural and historical context not only requires attention to stereotypes, 
but also to the intersectionality of these stereotypes within a particular context such as the United States.

Although the idea of intersectionality is widely accepted on a theoretical level, it is rarely investigated empirically. One exception is the study by Ghavami and Peplau (2013) who investigated whether the content of cultural stereotypes was different for the general social category (e.g., race or gender) compared to a specific social group (e.g., Black women). They asked more than 600 college students to list ten cultural stereotypes for either a gender group (men or women), an ethnic group (Black, White, Latino, Asian, or Middle Eastern), or a genderby-ethnic group (e.g., Black women, Black men, White women, White men, etc.). Analyzing more than 7,000 cultural stereotypes gathered from their sample, Ghavami and Peplau found that each gender-by-ethnic group elicited distinct stereotypes from the general ethnic group as well as the general gender group. For example, Black women were stereotyped as "promiscuous" and "overweight," whereas Black men were uniquely stereotyped as "rappers" and "quick to anger"; none of these stereotypes was listed as stereotypes about Black people, men, or women in general. This pattern was consistent across the ethnic groups in their study. White women, for example, were stereotyped as "ditsy" but Whites, in general, were characterized as intelligent. Asian men were stereotyped as "short" and "effeminate," whereas their female peers were defined as "studious," none of which was used to stereotype Asian people as a whole. In other words, Ghavami and Peplau's (2013) data illustrate that stereotypes about "race, class, and gender ... overlap, intersect, and fuse with each other in countless ways" (Omi \& Winant, 1994, p. 68) and the necessity of investigating identity with consideration of these interrelationships.

Our data also consistently show that when adolescents speak about their racial and ethnic identities they rely on an intersecting web of stereotypes to guide them (Rogers, 2013; Way et 
al., 2013). For example, when Roger (twelve years old), a Black male in one of our longitudinal studies of identity development, was asked about what he likes about being Black, he explains: I don't know. I just like being a Black person ... A lot of rappers are Black, a lot of basketball and football players are Black. It's like Michael Jordan was Black. He was like the best man in the NBA and he was Black also. It's like he's good and then he's Black also. Like somebody sees you and they see you playing basketball or football or listening to rap music, like they'll respect you for it. Although Roger may be correct that "a lot of rappers are Black" and many play sports, his response suggests that his identity as a Black person is constrained by these stereotypes about the possibilities for Black men. Roger's response also reveals the ways in which stereotypes intersect across social categories, with gender stereotypes (basketball player, rapper) being the lens through which Roger's race is experienced and negotiated.

Marcus, a thirteen-year-old in one of our studies, explains how his identity as a young Black male is directly shaped by society's stereotypes:

$[B e] c a u s e$ society has its boxes for everybody and they don't like it when you like jump outside of it...

Q: What kind of boxes are you in, or do you think society wants to put you in?

A: Like, the, well you're-never-going-to-be-anything 'cause you're in the Black box and I don't think you can do this cause you're Black ... Like Black kids are always doing the drugs .... and they're always doing sports, or always the one that's just trying to shoot somebody up, they're always the violent ones. ... You're not supposed to be a bookworm, be feminine, be gay. Oh yeah, you're 
Black, you're not supposed to be gay, you're supposed to have like fifty women and get a lot of people pregnant and then leave them all.

In this conversation about what it is like to be a Black male, Marcus articulates how his "expected" identity is based on a set of intersecting stereotypes about race, social class, gender, and sexuality that "box" him in.

The literature on Black masculinity (e.g., Cunningham, 1999; Davis, 2001; hooks, 2004; Stevenson, 1997) provides additional evidence of the "box" that Marcus speaks about, a set of rigid expectations that define the Black male identity as a stoic image of strength, independence, and hypersexuality referred to as the "cool pose" (Majors \& Billson, 1992). Davis (2001) finds, based on his observational research of Black boys in elementary school, that: "Black boys who do not meet the standards of an acceptable masculinity are treated as masculine mistakes," they are teased by their peers, called "gays" and "sissies," and relegated to socialize with girls (p. 147). Thus, in American culture, adhering to the Black male stereotype becomes essential to gaining and maintaining membership in the Black male social group.

Josh, a White American boy in one of our studies, also acknowledges the ways in which his Black male peers get boxed in and intersects social class and racial stereotypes in his description of what he likes about being White:

There are certainly advantages to being White ... Well if I were to walk into a store, no storekeeper would like be on us, but if a kid walked in with a doo-rag and like that and maybe some storekeeper would be on his alert. ... Just because people have these images in their heads of what certain groups of people are, which I find is messed up and stuff because — Like when I first came to my building on Washington Street I was like... Oh those [Black] guys are going to 
beat me up after school. But after being friends with [Black peers] [that] has

really changed a lot.

The meaning of whiteness for Josh is based on perceived advantages and disadvantages that hinge on intersecting stereotypes ("of what certain groups are") of race, social class, and gender, referring not simply to Black people but Black males from low-income families who are stereotyped to wear "doo-rags" and are followed by "storekeepers."

Lori, a Dominican-American student, also reveals the intersections of stereotypes in her ethnic identity and the relational nature of identity formation as she describes why she would want to be "White":

[I would like to be White because] people don't criticize them a lot ... like a lot [of] people they don't really say like "you're White" and all that, criticize you like they do to Dominicans. They say good things about White people, like they're rich and they like have [a] good education.

Lori suggests that it is not being White, per se, that she desires, it is the privilege and wealth that she perceives White people to have-the stereotypes about Whiteness in American culture-that makes being White desirable and distinct from her own ethnicity.

Michael, a thirteen-year-old Chinese-American boy, describes the "types" of Chinese students at his school and in the process illustrates how stereotypes about ethnicity and nationality collectively delineate and inform his identity:

[The Chinese who are not born here] they're different by how they act. ... They spit on the ground. Even though it was [in] the school. We don't care if you spit like outside in the street, but like in the school and the hallway, ya know, people gonna slip, like step on it. What's gonna happen? It starts fights and stuff. And 
then like, they dress differently, like, ya know, they really dress like so bright. We don't really like dress bright, and like shorts, even guys, like shorts up to like here ... And like they have clothes different from us. Like their brands, stuff like that. And their hairstyle all spiked up, and I'm like, uh.

Q: What group do you think you're in?

A: The Chinese kids that are like born here.....Mostly I hang out with them.

The immigrant youth in our studies often made such distinctions between the American-born and immigrant students, divisions that were grounded in intersecting stereotypes about nationality, social class, ethnicity, and sexuality, and they based their identification with and negotiation of these stereotypes (Way et al., 2013). Mary Waters's (1996) research on ethnic and racial identity among Caribbean immigrant youth revealed a similar pattern. A Trinidadian-American female in her research says:

My feelings are more like blacks ... I am lazy. I am really lazy and my parents are always making comments and things about how I am lazy. They are always like in Trinidad you could not be this lazy. In Trinidad you would have to go on working. (Waters, 1996, p. 72)

Weaving together stereotypes about race and nationality, specifically the belief that Black Americans are "lazy," these cultural expectations compose this young woman's interpretation of her own racial and ethnic identity. Such narratives underscore the ways that youth are engaged simultaneously with the macrolevel of cultural stereotypes and the microlevel of peer relationships.

Stereotypes of the intersection of race and sexuality were also evident in our studies. When asked what race he would like to be, a White boy in our study explains: "Black [because] 
you get to wear a lot more things that an average White person couldn't wear ... you get to wear pink without looking fruity or anything." In other words, being Black offers an opportunity to maintain a heterosexual image while at the same time having more flexibility in his appearance. For young White males who are often stereotyped as "soft" or "weak," it is the way that stereotypes about race and sexuality intersect that make being Black so attractive (Ghavami \& Peplau, 2013; Pascoe, 2007). Carter's (2006) research on the "acting White" phenomenon and Waters's research on identity among immigrant youth also unearthed gendered patterns whereby, for boys, "acting White" was equivalent to "talking soft" or "acting gay." Such research, as well as our own, illustrate how identities are entangled in a web of intersecting stereotypes.

Looking from the outside, stereotypes can be seen as an impetus for identity development, a macrocontextual factor that shapes the content and process of identity formation. At the same time, youth draw on and use stereotypes to make sense of their identities; thus, stereotypes are integral to and cannot be separated from the development of identities. In researching racial identity, Nasir and Shah (2011) find that stereotypes are more like cultural narratives than "mental representations." They state: "Narratives are not static—-they are continually taken up, reproduced, and resisted in multiple ways in daily life" (p. 26). Similarly, we find that stereotypes are both cultural phenomena and proximal "tools" that youth use as they formulate their identities. Youth, then, are not simply influenced by stereotypes in the construction of their identities, they react to them by resisting or accommodating to stereotypes (Anyon, 1984; Hammack, 2008; Spencer et al., 1997; Way, 2011: Way \& Rogers, in progress). Our research with adolescents has also revealed that youth define their ethnic and racial identities as "not being" an ethnic or racial stereotype (Rogers, 2013; Way et al., 2008; 2013). Black adolescents did not want to be perceived as lazy or dumb; Chinese American students did 
not want to be seen as nerds or victims of peer harassment and discrimination. Adolescents often speak more about who they do not want to be than who they want to be, and, even more, their ideal identities — who they aspire to be — are reflections of the stereotypes they most wish to avoid (Way et al., 2008; 2013).

For example, Monique, a thirteen-year-old African-American girl in one of our studies, responds to a question about what being African American means to her:

I'm trying to make a point of myself. I don't want to become-not another gangster, I don't want to become another thug in the street selling drugs being a hustler and I don't want to be another rapper, I don't want to be another hiphopper. I want to be myself. That's thinking smart. Thinking dumb means that like all Black people are supposed to become rappers, that's the stereotype. I'm not going to become no rapper. I'm going to become a singer maybe. I want to become a lawyer, I want to become a doctor, I want to become a veterinarian. A thirteen-year-old Chinese-American boy, Lee, responds similarly. When asked how being Chinese American is important for him, Lee says:

To be smart. I don't really try in school and I actually know the stuff. . . . Like strangers like always [think I am] a nerd ... so, then [someone called me] a nerd and I'm like, “Oh, I'm not a nerd." And I stood up for myself . . . I started, you know, stepping up to him. And he was [like] chill out. . . Because not every Chinese person has to be a nerd. . . . Like I'm not a good kid . . I'm not a nerd or any of that. 
Viewing themselves through the lens of society's stereotypes, Monique and Lee illustrate how the adolescents in our studies explicitly define who they are and want to be by delineating who they do not want to be-a direct response to the ethnic stereotypes.

John, a twelve-year-old African-American boy in one of our studies, also describes the stereotypes about African Americans and his self-definition that directly opposes them:

Well, I don't like basketball. Where I grew up, basketball, everybody, every Black person wants to be Michael Jordan. Um, um, most of us, like guys who wear their pants like to their thighs or their knees, Doo-rag, purple bandana or whatever, care more about getting Air Jordans than an "A" or get like a "C-" and don't care about grades or that stuff. African Americans [are] like the lowest percentage at graduation. They are only 48 Percent at graduation. . . . I'm not, I'm not like the average African American; like I'm different. I know that some of them, most of them probably like don't study or care about school, and I'm not like that. My backpack has a lot of books and you won't find a lot of African Americans reading Harry Potter.

Wen, a fourteen-year-old Chinese-American boy, responds similarly to describe his ethnic identity:

Q: What kind of things did you learn growing up about what it means to be Chinese?

A: You have to stand up for yourself or everybody's gonna pick on you if they think you're Chinese.

Q: Mm. How did you learn that? 
A: Cause people try to pick on me and I didn't let them pick on me. So, now they don't mess with me anymore.

Q: Who tried to pick on you?

A: Black kids and, Hispanic kids, like in 6th grade. Like when they first met me and everything. They thought I was just another regular Chinese kid, like a nerdy one and they tried to pick on me and stuff. So, I don't let them pick on me, so now they don't pick on me.

Like John, who identified himself as "not the average African American," Wen's ethnic identity is defined by not being a "regular Chinese kid." In essence, who they are is grounded principally in who they are not. At fourteen, Deon, a Black male in one of our studies, explains how he would describe himself to someone new:

I'm [a] tall, Black, handsome young man. ... I love God. I'm a positive man. Q: So what do you mean by positive man?

A: Um, not like the other men on the street that would, um, go and sell drugs, get high. And do the all the ordinary stuff like uh, like another Black man would: leave out on his wife or kids when she about to have a kid or somethin'. I don't care if I have twenty kids, I'm gonna be there for every last one of 'em. Because I wouldn't want to end up like my father. I wouldn’t want to see my kids cry every night tryin' to see where they're father at or nothin like that.

Deon draws a clear contrast between his ideal self as a "positive man" and feared self as a Black male stereotype (a drug user and absent father), revealing how identity is tied to that which he wishes to avoid.

Jaire, a fifteen-year-old Black male, describes what he likes most about himself: 
I love the fact that different people um, think of me to be um a more complex individual and a more intelligent individual. Because there's no 14-year-oldlet's be real, a young African American 14-year-old, you know, that can use different words in different situations and give his opinion about Barack Obama or the state the economy is in, the Iraq war, and different situations or the lesbian movement or whatever.

Jaire, like many of his peers, positions himself outside of the stereotyped category, defining himself in opposition to the cultural stereotypes. Implicitly, however, this strategy perpetuates the stereotypes by representing themselves as exceptions rather than questioning the truth of the stereotype itself. Robinson and Ward (1991; Ward, 1996) found a similar response pattern among Black girls and define it as "resistance for survival" - a response to stereotypes that is oriented toward "quick fixes" that, over the long term, advance neither individual nor group goals (Ward, 1996, p. 95). The alternative response is "resistance for liberation"-a critical consciousness that disrupts the cultural narrative, replacing "negative critique with positive recognition" of the self and others (Ward, 1996, p. 95). This tension of who to be and not to be is rooted in cultural stereotypes and produces either strategies for survival or for liberation.

The centrality of avoiding stereotypes also surfaces in the adolescent's motive to prove the stereotypes wrong (Suárez-Orozco, 2004). Like Imelda, a fourteen-year-old Dominican girl, who explains why it is important for her to be Dominican (vs. Dominican-American):

It's important for me to be Dominican because I guess I get to prove to everyone else that Dominicans can do something with their lives ... First of all I am proving it to myself and second of all I'm proving to like school, teachers, and I guess that's why I've kept up with all these grades ... I was the very first person 
in my family to ever do private school [in elementary school], so it's sort of a good feeling to know that I can say I got into a good school because I earned it. Ahmad, a fifteen-year-old Black male, answers a similar question about why being Black is important to him: "Well [being Black] is important 'cause, like, you don't want to live up to the, like the Caucasian people type of reputation they think you have ... I think that's just important for every Black male to prove "em wrong."

Devin, at fourteen years, explains why he likes being Black:

I'm just glad to be Black you know, even though there's like a lot of stereotypes. ...Like, Black men really don't like to grow up, either they're like drug dealers or gang bangers, or end up dead or something like that, or end up in jail. No, since I'm Black I feel like I gotta, you know, achieve somethin' other than that, you know? I've got goals to do.

Q: Do you like that?

A: Yeah! It keeps me focused. ...Like they say Black men probably won't make it, but I know I'm going to make it and even if I don't make it I'll still try to do something. I just can't—it's not me, I just can't be nothing. I've got to do something. ...I look in the mirror and wonder if you'll be a powerful Black man like Obama. Who knows I might be president!

This process of avoiding stereotypes is not just part of identity development, it is essential to it. Stereotypes fuel adolescents' self-perceptions and the identities they strive to construct or the "possible selves" they envision (Oyserman et al., 1995).

Thirteen-year-old Marcus, a Black male, explains: 
Well I guess some people are so used to seeing the gang bangers and the gangsters and stuff like that on the outside, so they think that every Black male is like that. But that's actually a stereotype. ...So um, we just trying to change their minds about Black men in general, being the best that we can be and getting our educations and proving them wrong.

Q: So how do you feel about that when you think about the stereotypes and that people think all Black males are gang bangers?

A: [sigh] I actually get kind of mad but I try to keep that anger under wraps cause you don't want that anger coming out in the wrong way. So um, I try to focus it in, do my schoolwork, so I can like prove, like break the stereotype. And like, I'd like to get out into the community and like tell people that you know this is not how we act. So I guess you could say, that I'm kind of inspired but then again I'm kind of like pissed off. That's kind of how I feel about it.

For Michael, a fourteen-year-old, proving the stereotypes wrong is how he defines being a Black male:

Q: Is being Black important to you?

A: Yeah, it is. I want to say because, um, there are very few African American males that graduate from college and succeed in life and I know that I'm gonna be one to succeed in life because of how my mother and father have been pushin' me through all my, um, years of getting my education. So, I just wanna prove the statistics wrong and help other people prove the statistics wrong that a Black man can graduate from college and be successful. 
The hope of being something other than a stereotype resonates with what Waters (1996) found among her immigrant Black youth who aspired to be more than "just" a Black American stereotype (p. 73).

The motive to avoid stereotypes operates for "positive" stereotypes as well. Lee (1994) coined the term "model minority myth" to describe a stereotype of Asian immigrants that they are smart, well-behaved, hardworking, and destined for success. Yet, as Lee's (1994) research revealed, this seemingly positive cultural narrative not only perpetuates negative stereotypes about immigrants from other countries but also puts inordinately high pressure on Asian immigrant youth and thus undermines their psychological and social well-being. For example, Andy, a twelve-year-old Chinese-American boy, describes how hard it is for him to receive math tutoring because he is Chinese:

That's the only thing I hate about school. And sometimes I'm trying to like concentrate. Sometimes I get bothered. Sometimes I don't get like one-on-one tutoring help. And I need it for math cause math is my worst subject. Q: Okay. So, tell me why would you like one on-one-tutoring help? A: Why I would want tutoring help is that I can understand more better . . . And sometimes I'm kind of a little bit timid cause when people are around me and I'll say something like "I don't get it" and then like I told the teacher to like, "Can you explain it?" And then some people were like, "Why do you need all that? Explain it again? Don't you get it?" And they look at me and then like, and then they're like, um, "You're supposed to know." Like that. But, I'm not good at math. So, what? 
Meiling, also twelve years old and Chinese American, articulates the explicit stereotype that Andy faces in receiving assistance with math:

Like there is a stereotype that a lot of Asian people are smart and people think that that's the case and then sometimes they feel like that you're not and then they look down on you? ... Like if I fail a test they'll say um why didn't you pass and stuff like that. Mm it kind of makes me feel a little bad, then it makes me want to improve the stereotype or to prove it's wrong. Well not that it's wrong, but that you shouldn't judge somebody by the stereotype.

At thirteen, Pam, a White American girl, gives a similar response when she explains what she doesn't like about being White:

Something that I feel uncomfortable about is that people expect more of you because you're White. Like if I was [an] African-American young man they would probably not expect me to smart or well educated. But, you know, because I am White they expect you know "Oh you must know this and you must know that." But, I don't know what the heck they're talking about.

Regardless of the valence of the stereotype, the adolescents in our studies and in other studies communicate that "you shouldn't judge somebody by a stereotype." Their narratives further reveal that stereotypes about race, ethnicity, sexuality, gender, social class, and/or nationality intersect with each other to form a core context within which identities are explored, constructed, and understood. These data offer a new perspective in which identity is concurrently a personal and social process and is considered part and parcel of a culture and a context.

Implications for Identity Research 
The work we have reviewed in this chapter underscores the important role of stereotypes in the identity development of ethnic and racial minority and majority youth and the extent to which the desire to avoid such stereotypes forms a crucial part of the process. The research furthermore suggests that cultural stereotypes are not only a context of identity development, but also a core feature of identity, and thus the constructs of identity and stereotypes should be examined together. In addition, the research suggests that a desire for a particular career, or what is typically considered a component of "personal identity," is just as "social" in its construction as a feeling of connectedness with one's ethnic group, a typical indicator of social identity. Both choices and feelings appear to be constructed in response to those around them and the expectations and stereotypes of the peers and adults in their lives. As Erikson indicated, identity development — at the personal and collective level—is inherently social, reflective of the cultural, historical, and economic context. This small but growing body of research on stereotypes and ethnic and racial identity development also raises questions that have the potential to shift the focus of research in the field of identity development.

For the remainder of the chapter, we discuss the implications of the patterns evident in our own research and the research of others on identity development (e.g., Nasir, 2011; Robinson $\&$ Ward, 1991; Spencer et al., 1997; Stevenson, 1997). Such research underscores the importance of investigating: (1) the macrocontext or the larger system of cultural beliefs that exist within contexts (e.g., the United States); (2) the relational nature of both personal and social identities; (3) the intersectionality of social categories and identities; (4) understanding identity development as a process, in part, of not becoming as well as becoming and (5) using methods that ask "why and what" in the study of racial and ethnic identity development.

\section{1) The Importance of the Macrocontext}


In its early years, the field of psychology distinguished itself from other social sciences by focusing on individual processes, such as mental functioning and cognition. The implicit assumption of much of the early work in psychology, with a few exceptions (e.g., Sullivan, 1956; Erikson, 1968; Lewin, 1951), was that such processes were, by and large, intrapersonal and universal or independent of culture. The introduction of the ecological model of human development marked a significant theoretical shift in psychology (Bronfenbrenner, 1977; Bronfenbrenner \& Morris, 2006). Bronfenbrenner (1977) conceptualized the developing child as nested within a set of contexts ranging from the microcontexts of family, schools, and peers to macrocontexts (e.g., religious and cultural beliefs and governmental laws) and argued that the ongoing, reciprocal interactions within these contexts facilitated and shaped developmental pathways. Following Bronfenbrenner's lead, alternative ecological models emerged that focused specifically on the macro- and microecologies of ethnic and racial minority youth (García-Coll et al., 1996; Spencer, 1995). For example, García-Coll and colleagues (1996) placed "social position variables" such as race and ethnicity in their model to emphasize how position on the social hierarchy has direct implications for developmental pathways. Similarly, Spencer (1995) revealed how children's experiences of stereotypes and discrimination serve as filters through which they engage with the social world around them. With the guidance of these ecological maps, psychologists began to acknowledge the ways that both the micro- and macrocontext shape human development (Bronfenbrenner, 1977; García-Coll et al., 1996; Spencer, 1995).

The study of identity development, however, with a few exceptions (e.g., Cunningham, 1999; Hammack, 2008; Nasir, 2011; Stevenson 1997; Spencer et al., 2004; Umaña-Taylor, 2004), has either treated identity as an individual-level variable or as a process that is shaped by the microcontexts of family and peers but not by macro-level cultural beliefs and practices. 
Microcontexts, however, such as parents' goals for their children have been shown to be directly influenced by larger cultural goals and ideologies (Tamis-LeMonda et al., 2007; Yoshikawa, Way, \& Chen, 2013). Moreover, culture in the field of psychology is still often conceptualized as the beliefs and practices of specific ethnic or racial groups rather than as the values and beliefs in the macrocontext of, for example, the United States. Research with American youth has shown that White, non-Jewish youth often believe that culture is reserved for "others" (Perry, 2001; Rogers et al., 2012). This pattern, however, reflects how American culture, as well as Whiteness, has been rendered invisible among the ethnic and racial majority in the United States (McIntosh, 1988).

In addition, studies of culture among ethnic and racial minority youth tend to focus on, for example, "Black culture" or "Chinese culture," but rarely examine how the macrocontext of American culture shapes the identities of ethnic and racial minority youth. Exceptions to this pattern include the investigation of immigrants and their families (e.g., Suárez-Orozco \& SuárezOrozco, 2001), suggesting that American culture is only relevant when one is not or is only newly American. Given that the beliefs, expectations, stereotypes, and practices evident in American culture is part of the macrocontext for those living in (and out of) the United States, examining the influence of such culture on identity development for American youth is important regardless of their ethnic or racial or immigrant status (Hammack, 2008; Steele, 2011). Investigating cultural stereotypes - or American beliefs about race, ethnicity, gender, sexuality, and class - in particular draws attention to the ways in which the macrocontext influences identity development.

\section{2) The Relational Nature of Personal and Social Identity}


The findings presented in this chapter point to the centrality of relationships and the social nature of both personal and social identity development. In a recent review of research on the self, neuroscientist Michael Bond reported: "[T]here is now a growing recognition that our sense of self may be a consequence of our relationships with others" (Bond, 2013, p. 41; emphasis added). In other words, rather than considering identity as the basis for building relationships with others, the data are pointing to the idea that relationships actually allow for a grounded sense of self (Gilligan, 1982). Our data also align with this shifting perspective, indicating how relationships between individuals and culture give rise to identities.

Our findings are consistent with a larger shift that is happening in the sciences of which David Brooks, the editorial writer at the New York Times, refers to as the "New Humanism" in the sciences. No longer is the emphasis on competition and individuality; research from the neurosciences and developmental psychology to evolutionary anthropology is underscoring the social, empathic, and interpersonal roots of our humanness (de Waal, 2006; Hrdy, 2009; Tomasello, 1999). Primatalogist Franz de Waal calls for a complete reassessment of how we understand what it means to be human, accounting for this new emphasis in the sciences on cooperation, empathy, and the importance social relations. Similarly, our research and that of many others suggest a need for an expansion of what we mean by and how we investigate identity processes and identity development to account for the relational or social nature of human beings. Without such an expansion, we are left with a constrained understanding of what it means to have an identity or for these identities to develop over time.

\section{3) The Intersectionality of Social Categories}

Scholars have long pointed out the intersecting nature of social categories and stereotypes (Collins, 2000; Omi \& Winant, 1994), but psychology, in particular, has been slow to integrate 
intersectionality perspectives into empirical research (Shields, 2008). Sociologist Paul Willis (1977) embedded the academic identities of urban Black males with the intersections of race, gender, and social class, and MacLeod's (1995) groundbreaking research on social class identity among working-class White males underscored the links between gender, masculinity, and social class. Similarly, Ladner's (1971) in-depth study of working-class Black females illustrated how the restrictions of social class, gender, and race shaped how Black females in her study constructed and experienced their identities as women.

Only recently have psychologists conducted empirical studies of identity intersectionality (e.g., Azmitia et al., 2008; Rogers, 2013; Settles, 2006; Spencer et al., 2004) and found that social categories do, in fact, intersect. Each of these works, and the data presented in this chapter, suggest, furthermore, that stereotypes play a key role in forging the connections among social categories. Ghavami and Peplau's (2013) study reviewed earlier in the chapter, in fact, demonstrates how stereotypes about ethnicity and gender overlap in the cultural construction of social groups. Thus, it is not simply that race and gender as social categories are related but that the stereotypes about these categories intersect to form unique identity constellations. In this way, integrating stereotypes into identity theory may indeed provide a tangible method for translating intersectional theory into empirical study.

From a developmental perspective, it is also of interest to consider whether and how intersectionality of social categories changes over time. Existing studies of intersectionality do not explicitly address the developmental nature of intersectionality; thus, it remains unclear whether or how the link between stereotypes in identity formation changes across time and social contexts, perhaps being more salient at different developmental periods, among certain social groups, or in more ethnically or racially diverse social settings. Azmitia and colleagues' (2008) 
data with college-aged students suggest a development trend whereby, as adolescents transitioned through college, they became increasingly aware of, and perhaps able to articulate, the ways multiple social group expectations shaped their identities and career choices. It remains unclear, however, the age at which an awareness of intersectionality might emerge. For example, do children see cultural stereotypes about White girls to be distinct from stereotypes about White men and White people in general? Do they see the stereotypes that exist for Black women compared to White women, and how do such awareness then shape their own identity development? We know that generally children are aware of gender before they are aware of race (Ruble et al., 2004), but, from the perspective of intersectionality, it is also of interest when they begin to view gender through a racial lens and vice versa. Such questions will push the scientific study of identity to explore the more dynamic and lived experience of identity in culture and context.

\section{4) Becoming and Not Becoming}

We find in our research that adolescents both become as well as avoid becoming stereotypes and that these processes spur identity choices and affiliations. In other words, adolescents both resist and accommodate to images projected onto them by others in their distal and proximal contexts in the construction of their own identities (Anyon, 1984; Brown \& Gilligan, 1992; Robinson \& Ward, 1991; Spencer et al., 1997). Writing about the identities of Black girls and women, Robinson and Ward (1991) find girls (and boys) engage in "resistance for survival" -- short-term strategies for survival to negative life circumstances (e.g., being a teenage mother or gang member), or "resistance for liberation" - a strategy that fosters long-term health for the self and others (e.g., graduating from high school). This process of resistance for survival and resistance for liberation is similar to the constructs of accommodation and resistance to stereotypes. While 
Robinson and Ward refer to both strategies as resistance, our findings suggest that resistance for survival is, in fact, accommodation to mainstream cultural stereotypes and resistance for liberation is resistance to cultural beliefs that are bad for one's wellbeing.

The theme of resisting becoming a stereotype or "resistance for liberation" has been found in other studies as well (Brown \& Gilligan, 1992; Rogers, 2013; Ward, 1996; Way, 2011; Way et al., 2013). Such studies suggest that youth actively resist cultural messages that are bad for their wellbeing (Brown, 1999; Brown \& Gilligan, 1992; Cvencek, Nasir, O’Connor, Wischnia, \& Meltzoff, In Press; Rogers, 2012; Rogers \& Way, In Press; Thorne \& McLean, 2003; Way, 2011; Way et al., 2013). Not only do girls and boys resist such messages, this resistance has been found to be linked to psychological and social well-being (Gupta et al., 2013; Santos, 2010; Way \& Rogers, in progress). For example, Santos (2010) measured boys' resistance to masculine norms and found that boys who reported higher levels of resistance in their friendships, in particular, reported higher levels of psychological adjustment over time. In a separate study, he found a positive link between boys' resistance to masculine norms and greater levels of engagement in school (Santos, Galligan, Pahlke, \& Fabes, 2013). Examining how adolescents resist and accommodate to cultural stereotypes in the construction of their ethnic and racial identities seems like an important direction for future studies.

\section{5) Expanding the Methodology in the Study of Identity}

Scholars have long argued that open-ended and narrative methods are necessary to provide meaning to the identity literature (McAdams, 2013; Syed \& Azmitia, 2008, 2010; Way et al., 2008). Indeed, our findings underscore the need to diversify our methodological toolkit. Although survey methods provide critical insight into the correlates associated with various levels of ethnic or racial identity (e.g., Ashmore et al., 2004; Sellers et al., 1998) and address the 
questions of "how much," they do not address the questions of "why or what" or the ways the macrocontext influences the development and meaning of these dimensions of identity. In our studies, we have found that it is often in the language that young people use to describe their ethnic and racial identities that we hear and see the micro- and macrocontext of identity (Rogers \& Way, In Press; Way, 2011). The finding that youth "avoid" stereotypes and define themselves in opposition to them, for example, is evident in the language of adolescents. Identity research must pay greater attention to the ways in which the culture and context is revealed in the language of adolescents and the ways that this language provides insight into the process of identity development.

\section{Conclusion}

The data presented in this chapter illustrate that identity is a cultural, contextual, and relational process. To more thoroughly understand how identities develop, what they mean, and how they matter, we need more research that conceptualizes the personal and the social as social. Research on identities, in other words, needs to return to its theoretical roots and explore how cultures and contexts give identities their meanings. The data over the past few decades suggest that identities and the macrocontext are bound tightly together, with the macrocontext shaping the identities constructed and the identities shaping the meaning and understanding of the macrocontext. Understanding ethnic and racial identity within the micro and macrocontexts in which they exist allows for a more theoretically rich understanding of identities and identity development.

\section{References}


Anyon, J. (1984). Intersections of gender and class: Accommodation and resistance by workingclass and affluent females to contradictory sex role ideologies. Journal of Education, Boston, 166, 25-48.

Ashmore, R. D., Deaux, K., \& McLaughlin-Volpe, T. (2004). An organizing framework for collective identity: Articulation and significance of multidimensionality. Psychological Bulletin, 130, 80-114.

Azmitia, M., Syed, M., \& Radmacher, K. (2008). The intersections of personal and social identities. San Francisco: Jossey-Bass.

Bond, M. (2013, Feb. 28). The self: Why are you like you are? New Scientist Magazine, The Great Illusion of the Self (pp. 41-43).

Bronfenbrenner, U. (1977). Toward an experimental ecology of human development. American Psychologist, 32, 513-531.

Bronfenbrenner, U., \& Morris, P. A. (2006). The bioecological model of human development. In R. M. Lerner and W. Damon (Eds.) Handbook of child psychology (6th ed.). Theoretical models of human development (pp. 793-828). Hoboken, NJ: John Wiley \& Sons.

Brown, L. M. (1999). Raising their voices: The politics of girls' anger. Cambridge, MA: Harvard University Press.

Brown, L. M., \& Gilligan, C. (1992). Meeting at the crossroads: Women's psychology and girls' development. Cambridge, MA: Harvard University Press.

Carter, P. L. (2006). Straddling boundaries: Identity, culture, and school. Sociology of Education, $79,304-328$. 
Chavous, T. M., Bernat, D. H., Schmeelk-Cone, K., Caldwell, C. H., Kohn-Wood, L., \& Zimmerman, M. A. (2003). Racial identity and academic attainment among African American adolescents. Child Development, 74, 1076-1090.

Chu, J. Y. (2004). A relational perspective on adolescent boys' identity development. In N. Way, \& J. Y. Chu (Eds.), Adolescent boys: Exploring diverse cultures of boyhood. (pp. 78104). New York: New York University Press.

Chua, P., \& Fujino, D. C. (2008). Negotiating new Asian-American masculinities: Attitudes and gender expectations. Journal of Men's Studies, 7, 391-413.

Cole, M. (1998). Cultural psychology: A once and future discipline. Cambridge, MA: Harvard University Press.

Collins, P. H. (2000). Black feminist thought: Knowledge, consciousness, and the politics of empowerment. New York: Routledge.

Cooley, C. H. (1902). Human nature and the social order. New York: Scribner.

Cote, J. E., \& Schwartz, S. J. (2002). Comparing psychological and sociological approaches to identity: Identity status, identity capital, and the individualization process. Journal of Adolescence, 25, 571-586.

Cross, W. (1991). Shades of Black: Diversity in African American identity. Philadelphia: Temple University Press.

Cunningham, M. (1999). African-American adolescent males' perceptions of their community resources and constraints: A longitudinal analysis. Journal of Community Psychology, 27, $569-588$. 
Cvencek, D. Nasir, N. S., O’Connor, K., Wischnia, S. A., \& Meltzoff, A. N. (In Press). “They say Chinese people are the best at math": Elementary- and middle-school students' explicit and implicit math-race stereotypes. Journal of Adolescent Research.

Davis, J. E. (2001). Transgressing the masculine: African American boys and the failure of schools. In W. Martino, \& B. Meyenn (Eds.), What about the boys?: Issues of masculinity in schools (pp. 140-153). Maidenhead, UK: Open University Press.

de Waal, F. (2006). Primates and philosophers: How morality evolved. Princeton, NJ: Princeton University Press.

Delpit, L. D (1995). Other people's children: Cultural conflict in the classroom. New York: New Press.

Erikson, E. H. (1968). Identity, youth, and crisis. New York: W. W. Norton.

Fordham, S. (1988). Racelessness as a factor in black students' school success: Pragmatic strategy or pyrrhic victory? Harvard Educational Review, 58, 54-84.

Fordham, S. (1993). "Those loud Black girls": (Black) women, silence, gender "passing" in the academy. Anthropology and Education Quarterly, 24, 3-32.

Fordham, S., \& Ogbu, J. (1986). Black students' school success: Coping with the burden of “acting white." Urban Review, 18, 1-31.

García-Coll, C., Lamberty, G., Jenkins, R., Pipes McAdoo, H., Crnic, K., Wasik, B. H., \& et al. (1996). An integrative model for the study of developmental competencies in minority children. Child Development, 67, 1891-1914.

Gilligan, C. (1982). In a different voice: Psychological theory and women's development. Cambridge, MA: Harvard University Press. 
Ghavami, N., \& Peplau, L. A. (2013). An intersectional analysis of gender and ethnic stereotypes: Testing three hypotheses. Psychology of Women Quarterly, 37, 113-127.

Gupta, T., Way, N., McGill, R., Hughes, D., Santos, C., Jia, Y., Yoshikawa, H., Chen, X., \& Deng, H. (2013). Gender-typed behaviors in friendships and well-being: A cross-cultural study of Chinese and American boys. Journal of Research on Adolescence, Special Issue: Adolescents in the Majority World, 23, 57-68.

Hammack, P. L. (2008). Narrative and the cultural psychology of identity. Personality and Social Psychology Review, 12, 222-247.

Hammack, P. L., \& Cohler, B. J. (2011). Narrative, identity, and the politics of exclusion: Social change and the gay and lesbian life course. Sexuality Research and Social Policy, 8(3), $162-182$.

Hirschfeld, L. A. (1996). Race in the making: Cognition, culture, and the child's construction of human kinds. Cambridge, MA: MIT Press.

hooks, b. (2004). We real cool: Black men and masculinity. New York: Routledge.

Hrdy, S. B. (2009). Mothers and others: The evolutionary origins of mutual understanding. Cambridge, MA: Harvard University Press.

James, W. (1890). The principles of psychology (vol. I). New York: Henry Holt and Co.

Ladner, J. A. (1971). Tomorrow's tomorrow: The black woman. Garden City, NY: Doubleday.

Lee, S. J. (1994). Behind the model-minority stereotype: Voices of high-and low-achieving Asian American students. Anthropology \& Education Quarterly, 25, 413-429.

Lei, J. L. (2003). (Un)Necessary toughness? Those "loud Black girls" and those "quiet Asian boys." Anthropology and Education Quarterly, 34, 158-181.

Lewin, K. (1951). Field theory in social science. New York: Harper 
López, N. (2003). Hopeful girls, troubled boys: Race and gender disparity in urban education. New York: Routledge.

MacLeod, J. (1995). Ain't no makin' it: Aspirations and attainment in a low-income neighborhood. Boulder, CO: Westview Press.

Majors, R., \& Billson, J. M. (1992). Cool pose: The dilemmas of Black manhood in America. New York: Lexington Books.

Marcia, J. E. (1966). Development and validation of ego-identity status. Journal of personality and social psychology, 3, 551-558.

McAdams, D. P. (1990). Unity and purpose in human lives: The emergence of identity as a life story. In A. I. Rabin, R. A. Zucker, R. A. Emmons, \& S. Frank (Eds.), Studying persons and lives (pp. 148-200). New York: Springer.

McAdams, D. P. (2001). The psychology of life stories. Review of General Psychology, 5, 100-122.

McAdams, D. P. (2013). The redemptive self: Stories Americans live by. New York, NY: Oxford University Press

McIntosh, P. (1988). White privilege: Unpacking the invisible knapsack. Race, Class, and Gender in the United States: An Integrated Study, 4, 165-169.

Mead, G. H. (1934). Mind, self, and society. Chicago: University of Chicago Press.

Nasir, N. S. (2011). Racialized identities: Race and achievement among African American youth. Stanford, CA: Stanford University Press.

Nasir, N., \& Shah, N. (2011). On defense: African American males making sense of racialized narratives in mathematics education. Journal of African American Males in Education, $23-45$. 
Orlofsky, J. L., Marcia, J. E., \& Lesser, I. M. (1973). Ego identity status and the intimacy versus isolation crisis of young adulthood. Journal of Personality and Social Psychology, 27, 211-219.

Omi, M., \& Winant, H. (1994). Racial formation in the United States: From the 1960s to the 1990s. New York: Routledge.

Oyserman, D., Grant, L., \& Ager, J. (1995). A socially contextualized model of African American identity: Possible selves and school persistence. Journal of Personality and Social Psychology, 69, 1216-1232.

Paabo, S. (2001). The human genome and our view of ourselves. Science, 291, 1219-1220.

Pascoe, C. J. (2007). Dude, you're a fag: Masculinity and sexuality in high school. Los Angeles: University of California Press.

Perry, P. (2001). White means never having to say you're ethnic/racial: White youth and the construction of "cultureless" identity. Journal of Contemporary Ethnography, 30, 56-91.

Phinney, J. S. (1990). Ethnic identity in adolescents and adults: Review of research. Psychological Bulletin, 108, 499-514.

Phinney, J. S. (1992). The multigroup ethnic identity measure: A new scale for use with diverse groups. Journal of Adolescent Research, 7, 156-176.

Quintana, S. M. (2007). Racial and ethnic identity: Developmental perspectives and research. Journal of Counseling Psychology. Special Issue: Racial and Ethnic Identity Theory, Measurement, and Research in Counseling Psychology: Present Status and Future Directions, 54, 259-270. 
Robinson, T., \& Ward, J. V. (1991). "A belief in self far greater than anyone's disbelief”: Cultivating resistance among African American female adolescents. Women \& Therapy. Special Issue: Women, Girls \& Psychotherapy: Reframing Resistance, 11, 87-103.

Rogers, O. (2012). Young, Black, and male: Exploring the intersections of racial and gender identity in an all-Black, all-male high school. Available from ProQuest Dissertation Abstracts (UMI No. 10197).

Rogers, O. (2013). Black males narrating identities and stereotypes in an all-Black male high school. In S. Sirin (Chair), Negotiating cultural identities among youth. Paper presented at biennial meeting for Society for Research on Child Development. Seattle, WA.

Rogers, O. \& Way, N. (In Press). Using semi-structured interviews to examine adolescent racialethnic identity. Invited chapter in C. Santos \& A. J. Umaña-Taylor (Eds.) Studying ethnic identity: Methodological advances and consideration for the future. APA

Rogers, O., Zosuls, K., Halim, M. L., Ruble, D., Hughes, D, \& Fuligni, A. (2012). Meaning making in middle childhood: An exploration of the meaning of ethnic identity. Cultural Diversity and Ethnic Minority Psychology, 18, 99-108.

Rogoff, B. (2003). The cultural nature of human development. New York: Oxford University Press.

Ruble, D. N., Alvarez, J., Bachman, M., Cameron, J., Fuligni, A., Coll, C. G., \& Rhee, E. (2004). The development of a sense of "we": The emergence and implications of children's collective identity. In M. Bennett, \& F. Sani (Eds.), The development of the social self (pp. 29-76). New York: Psychology Press. 
Santos, C. E. (2010). The missing story: Resistance to norms of masculinity in the friendships of adolescent boys. Available from ProQuest Dissertations and Theses database. (UMI No. 3426967).

Santos, C. E., Galligan, K., Pahlke, E., \& Fabes, R. (2013). Gender-typed behaviors, achievement, and adjustment among racially and ethnically diverse boys during early adolescence. American Journal of Orthopsychiatry 83, 252-264

Schwartz, S. J. (2005). New identity for identity research: Recommendations for expanding and refocusing the identity literature. Journal of Adolescent Research, 20, 293-308.

Seaton, E. K., Scottham, K. M., \& Sellers, R. M. (2006). The status model of racial identity development in African American adolescents: Evidence of structure, trajectories, and well-being. Child Development, 77, 1416-1426.

Segall, M. H. (1999). Why is there still racism if there not such thing as "race"? In W. J. Lonner, D. L. Dinnel, D. K. Forgays, \& S. A. Hayes (Eds.), Merging past, present, and future in cross-cultural psychology. Lisse: Swets \& Zeitlinger.

Sellers, R. M., Smith, M. A., Shelton, J. N., Rowley, S. A. J., \& Chavous, T. M. (1998). Multidimensional model of racial identity: A reconceptualization of African American racial identity. Personality and Social Psychology Review, 2, 18-39.

Settles, I. H. (2006). Use of an intersectional framework to understand Black women's racial and gender identities. Sex Roles, 54, 589-601.

Shek, Y. L. (2006). Asian American Masculinity: A Review of the Literature. Journal of Men's Studies, 14, 379-391.

Shields, S. A. (2008). Gender: An intersectionality perspective. Sex Roles, 59, 301-311. 
Slaughter-Defoe, D. T. (2012). Introduction in D. T. Slaughter-DeFoe (Ed.) Racial stereotyping and child development. Psychotherapy and Psychosomatics, 81(4), 199-264. Basal, Switzerland: Karger.

Spencer, M. B. (1995). Old and new theorizing about African-American youth: A phenomenological variant of ecological systems theory. In R. L. Taylor (Ed.), Black youth: Perspectives on their status in the United States (pp. 37-69). Westport, CT: Praeger.

Spencer, M. B., Dupree, D., \& Hartmann, T. (1997). A phenomenological variant of ecological systems theory (PVEST): A self-organization perspective in context. Development and Psychopathology, 9, 817-833.

Spencer, M. B., Fegley, S., Harpalani, V., \& Seaton, G. (2004). Understanding hypermasculinity in context: A theory-driven analysis of urban adolescent males' coping responses. Research in Human Development, 1, 229-257.

Stagnor, C., \& Schaller, M. (1996). Stereotypes as individual and collective representations. In C. N. Macrae, C. Stagnor, \& M. Hewstone (Eds.), Stereotypes and stereotyping (pp. 337). New York: Guilford Press.

Steele, C. M. (2011). Whistling Vivaldi: How stereotypes affect us and what we can do. New York: W. W. Norton \& Company.

Stevenson, H. C. (1997). "Missed, dissed, and pissed": Making meaning of neighborhood risk, fear and anger management in urban Black youth. Cultural Diversity and Mental Health, $3,37-52$.

Suárez-Orozco, C. (2004). Formulating identity in a globalized world. In M. M. Suárez-Orozco, \& D. B. Qin-Hilliard (Eds.), Globalization: Culture and education in the new millennium. (pp. 173-202). Berkeley, CA: University of California Press. 
Suárez-Orozco, C., \& Suárez-Orozco, M. (2001). Children of Immigration. Cambridge, MA: Harvard University Press.

Syed, M., \& Azmitia, M. (2008). A narrative approach to ethnic identity in emerging adulthood: Bringing life to the identity status model. Developmental Psychology, 44, 1012-1027.

Syed, M., \& Azmitia, M. (2009). Longitudinal trajectories of ethnic identity during the college years. Journal of Research on Adolescence, 19, 601-624.

Syed, M., \& Azmitia, M. (2010). Narrative and ethnic identity exploration: A longitudinal account of emerging adults' ethnicity-related experiences. Developmental Psychology, 46, 208-219.

Tajfel, H. (1981). Human groups and social categories: Studies in social psychology. Cambridge, UK: University of Cambridge Press

Tajfel, H., \& Turner, J. C. (1986). The social identity theory of intergroup behavior. In S. Worchel, \& W. Austin (Eds.), Psychology of inter-group relations (pp. 7-24). Chicago: Nelson Hall.

Tamis-LeMonda, C. S., Way, N., Hughes, D., Yoshikawa, H., Kalman, R. K., \& Niwa, E. Y. (2007). Parents' goals for children: The dynamic coexistence of individualism and collectivism in cultures and individuals. Social Development, 17, 183-209.

Thorne, A., \& McLean, K. C. (2003). Telling traumatic events in adolescence: A study of master narrative positioning. In R. Fivush and C. A. Haden (Eds.) Autobiographical memory and the construction of a narrative self: Developmental and cultural perspectives (pp. 169185).

Tomasello, M. (1999). The cultural origins of human cognition. Cambridge, MA: Harvard University Press. 
Umaña-Taylor, A. J. (2004). Ethnic identity and self-esteem: Examining the role of social context. Journal of Adolescence, 27, 139-146.

Ward, J. V. (1996). Raising resisters: The role of truth telling in the psychological development of African American girls. In B. J. R. Leadbeater, \& N. Way (Eds.), Urban girls: Resisting stereotypes, creating identities (pp. 85-99). NY: New York University Press.

Waters, M. C. (1996). The intersection of gender, race, and ethnicity in identity development of Caribbean American teens. In B. J. R. Leadbeater, \& N. Way (Eds.), Urban girls: Resisting stereotypes, creating identities (pp. 65-81). NY: New York University Press.

Way, N. (2011). Deep secrets: Boys' friendships and the crisis for connection. Cambridge, MA: Harvard University Press.

Way, N., Hernandez, M. G., Rogers, O., \& Hughes, D. (2013). "I'm not going to become no rapper": Stereotypes as a context of ethnic and racial identity development." Journal of Adolescent Research, 28, 407-430.

Way, N. \& Rogers, O. (in progress). Resistance as a developmental process. In preparation for submission to Human Development.

Way, N., Santos, C., Niwa, E. Y., \& Kim-Gervey, C. (2008). To be or not to be: An exploration of ethnic/racial identity development in context. In M. Azmitia, M. Syed, \& K. Radmacher (Eds.), The intersections of personal and social identities: New directions for child and adolescent development (pp. 61-78). San Francisco: Jossey-Bass.

Willis, P. (1977). Learning to labor: How working class kids get working class jobs. New York: Columbia University Press.

Yoshikawa, H., Way, N., \& Chen (2013).Large-scale economic change and youth development: The case of urban China. New Directions of Youth Development, 135, 39-55. 


\section{Endnotes}

${ }^{1}$ The four main studies we draw data from for this chapter are: The Connections Project, Project RAP, The RAP Project, and The Identity Project. The Connections study and Project RAP, funded by the National Science Foundation and The William T. Grant Foundation, were longitudinal, mixed-method research projects conducted by Niobe Way in coeducational high schools in the northeast. These projects were focused on adolescents' friendships during high school. The RAP project was another mixed-method, longitudinal project conducted by Diane Hughes and Niobe Way at the Center for Research on Child Development and Education at New York University and was funded by the National Science Foundation. This project was a six-year, mixed method, longitudinal project that included six middle schools that took place from sixth to eleventh grade. The focus of the project was on the ways in which the contexts of school, families and peers, shape the social, emotional, and cognitive development of youth. The Identity Project, supported by the Spencer Foundation, was a two-year dissertation study conducted by Onnie Rogers at a single-sex high school in a midwestern urban city. This study examined racial and gender identity development as boys transitioned from co-ed middle schools and into an all-male high school. 